\title{
Barriers to accessing support for mental health issues at university
}

Eilidh Cage $^{1}$, Melissa Stock ${ }^{1}$, Alex Sharpington $^{1}$, Emma Pitman $^{1}$ and Rachel Batchelor ${ }^{1}$

${ }^{1}$ Royal Holloway, University of London, Surrey, UK

Corresponding author: Dr Eilidh Cage, eilidh.cage@rhul.ac.uk; Twitter: @DrEilidh

Manuscript accepted for publication in Studies in Higher Education, 31/10/18

This is an Accepted Manuscript of an article published by Taylor \& Francis Group in Studies in Higher Education on 13 Nov 2018, available online http://www.tandfonline.com/10.1080/03075079.2018.1544237 


\section{Abstract}

Student mental health is an issue of great concern for universities, with rising numbers of mental health problems being reported and students reporting issues with accessing support. The current study, using a participatory research framework, investigated the possible barriers preventing students from accessing support, in terms of help-seeking intentions and actual help-seeking behaviour. Three hundred and seventy-six current UK students completed a questionnaire which measured help-seeking and possible barriers including perceived public stigma, self-stigma, educational impact, disclosure, coping and current mental health symptoms. Findings indicated that selfstigma in particular was a barrier to accessing support. Disclosure, educational impact, previous diagnosis, suspected diagnosis and mental health symptoms also interacted with help-seeking. These findings have implications for universities in tackling the barriers preventing students accessing support for their mental health.

Key words: student mental health; student support; barriers; student wellbeing; selfstigma

Words: 6993 
Mental health issues in university students is an issue of utmost importance: in the academic year 2016/17, there were 53,045 students with a recorded mental health condition in the UK (Higher Education Statistics Authority 2018). Two percent of first-year students in the UK disclosed a mental health condition in 2015/16, five times that reported in 2006/7 (Thorley 2017). Many students likely experience mental health difficulties, but these go unreported or the students do not utilise support services (Eisenberg, Golberstein and Gollust 2007). University students appear to be at a higher risk of developing mental health problems (Eskin et al. 2016), report that they frequently miss academic commitments due to their mental health (Eisenberg et al. 2007) and those with mental health difficulties are more likely to drop out of university (Thorley 2017). Therefore, it is vital student mental health is understood to ensure students access the necessary support for their needs while at university.

However, students may not access support for their mental health: Rosenthal and Wilson (2008) found that over three quarters of students with significant mental distress did not receive counselling. There may be several barriers preventing students from accessing support, including a lack of available counsellor appointments (Mowbray et al. 2006). Universities with on-campus General Practitioners (GPs) in the U.S. have been criticised for providing minimally adequate treatment for depression (Eisenberg and Chung 2012). A lack of knowledge about available treatments may also play a role, with a third of students not knowing where to access support (NUS-USI 2017). Finally, students may not access support because they do not believe they need treatment, even if they have an elevated risk for suicide (Czyz et al. 2013).

Stigma - how society reacts towards people with mental health difficulties - could also be a barrier to accessing support (Bathje and Pryor 2011). People with mental health conditions are at risk of discrimination, with the label "mentally-ill" associated with negative connotations (Corrigan 2004). In interviews with UK students, Quinn et al. (2009) noted 
reluctance to seek support was linked to perceptions of stigma. The experience of stigma likely exacerbates mental health problems and may prevent people from seeking help (Vidourek et al. 2014). Students may also experience self-stigma - an individual's own internalised attitudes, often adopting the stigmatising public discourse towards their own mental health (Corrigan, Watson and Barr 2006) and self-stigmatising the act of help-seeking (Tucker et al. 2013). Self-stigma and public stigma independently contribute to mental health help-seeking (Bathje and Pryor 2011). In one systematic review, both types of stigma were the biggest barrier to help-seeking for young people (Gulliver, Griffiths and Christensen 2010).

A systematic review conducted by Clement et al. (2015) found stigma was only the fourth most important barrier to help-seeking in the general population. Instead, concerns around disclosing mental health issues was the top barrier. Individuals may differ in their willingness to disclose mental health difficulties due to concerns over shame and embarrassment (Kahn and Hessling 2001). Gulliver et al. (2010) found that concerns around confidentiality after disclosure represented a major source of concern for many young people. An individual may fear that a breach of confidentiality following disclosure may lead to stigma from peers or family (Gulliver et al. 2010). Consequently, this fear may prevent an individual from disclosing their mental health issues to a professional.

The ability to cope with psychological distress must also be considered - it may be that individuals who are good at coping are less likely to seek help. The act of coping efforts to reduce or prevent stress, harm or threat (Carver and Connor-Smith 2010) - is often vital in determining an individuals' psychological adjustment and well-being (Monzani et al. 2015). Actively attempting to improve circumstances and solve problems is advantageous (Carver and Connor-Smith 2010), linking to higher rates of attained goals and positive affect (Mackay et al. 2011), as well as higher academic performance (Struthers, Perry and Menec 
2000). Thus, those with a higher ability to cope may not seek help, due to lower perceived need.

Individual differences in help-seeking intentions should also be considered as a barrier to accessing support. With help-seeking intentions, people may report that they plan to seek help if they experience psychological distress (Wilson et al. 2005). The theory of planned behaviour suggests that intention is the strongest predictor of actual behaviour (Abraham, Sheeran and Henderson 2011). The theory argues that intention is predicted by a person's attitude towards the specific behaviour, their subjective norm of significant others (Montano and Kasprzyk 2015) and perceived control in the ability to carry out the behaviour (Abraham et al. 2011). However, intentions do not necessarily translate into actual behaviour (de Bruijn, Out and Rhodes 2014), particularly in the domain of mental health (Li 2016). Rickwood et al. (2005) conducted a systematic review of adolescents' help-seeking intentions for mental health problems and found mixed evidence on the relationship between intentions and behaviour. The relationship between intention and actual help-seeking has been suggested to be dependent upon specific mental health problems and barriers people face (Rickwood et al. 2005).

As shown by the number of students with mental illness, and the noted challenges in receiving adequate support, there is an issue with students accessing and receiving treatment from mental health issues while at university. Highlighting the barriers that students face may be the first step to implementing strategies to overcome these barriers. The current study therefore aimed to examine the possible barriers preventing UK students from accessing support for mental health issues. Based on the discussed literature, the following variables were examined as barriers to both intentions to seek help and actual help-seeking behaviour: perceived public stigma, self-stigma, educational impact, disclosure, coping and current mental health functioning in terms of depression, anxiety and stress. We hypothesised that 
there would be significant barriers to students' accessing support for their mental health needs. 


\section{Methods}

\section{Participants}

Three hundred and seventy-six current students took part with a mean age of $20.73(S D=$ 3.34). Most participants were female $(83.5 \%, n=314$; male $15.7 \%, n=59$; other/prefer not to say $.8 \%, n=3$ ). Eighty-two percent were born in the United Kingdom. Most were White British (76.9\%) or from another White Caucasian background (12\%); 5.6\% were Asian/Asian British, 3.7\% were multi-ethnic and .5\% were Black/Black British. Most were heterosexual (76.8\%) with $12.6 \%$ reporting that they were bisexual and $7.7 \%$ homosexual. Participants were recruited via word of mouth, social media and the UK student mental health charity 'Student Minds’ website.

Information regarding university and student status is displayed in Table 1 . This information shows that most participants were undergraduate, full-time Home students, recruited from the South East of England.

\section{[Insert Table 1 here]}

Ethical approval was obtained via [blinded for peer review] and all participants gave full informed consent before participating.

\section{Materials}

Participants completed an online survey, with the following measures presented using the 'Qualtrics' survey software.

Help-seeking.

Help-seeking intentions for mental health problems was measured using the General Help Seeking Questionnaire (Wilson et al. 2005). Participants rated their likelihood of seeking help for personal or emotional problems, from four informal sources (parents, other family 
member, friends and intimate partner) and three formal sources (GP, mental health professional and helpline), on a 7-point Likert scale ('extremely unlikely' (1) to 'extremely likely' (7)). Higher scores represented higher intentions to seek help. Participants also rated the item 'I would not seek help from anyone'. Responses were categorised into three subscales (informal or formal source, or no-one). Internal consistency was acceptable for intentions from informal sources $(\omega=.62)$ and from formal sources $(\omega=.69)$.

Actual help-seeking behaviour was measured by asking participants "which of the following services have you accessed with regards to your mental health since you have been at university?" Participants could select from nine sources, such as a mental health advisor, counsellor or GP. Participants could also indicate if they had not accessed any support. Responses were coded into either 'accessed support of any form' or 'none'.

\section{Perceived Public Stigma.}

Perceived stigma for receiving psychological help was measured using the Adapted Stigma Scale (Golberstein, Eisenburg and Gollust 2008). Participants rated agreement with five statements, such as 'It is a sign of personal weakness or inadequacy to receive treatment for mental health problems'. Each item was scored on a 5-point scale ('strongly disagree' (1) to 'strongly agree' (5)). Scores were summed to derive a total ranging from 5 to 25 , with higher scores representing higher stigma. Internal consistency was good $(\omega=.77)$.

\section{Self-Stigma.}

Self-stigma was measured using the Self-Stigma of Seeking Help Scale (Vogel, Wade and Haake 2006). Participants rated agreement with ten statements on a 5-point scale ('strongly disagree' (1) to 'strongly agree' (5)), such as 'If I went to a therapist, I would be less satisfied with myself'. Scores were summed to obtain a total ranging between 10 and 50, with higher scores indicating a greater self-stigma. Internal consistency was very good $(\omega=.87)$. 


\section{Educational impact.}

Impact on academic functioning was measured with two questions rated on a 5-point scale ('never' (1) to 'a great deal' (5)) from Einsberg et al. (2007): 'How often have you missed classes/other academic obligations in the past four weeks due to mental health difficulties?' and 'How often has your academic performance been affected in the past four weeks due to mental health difficulties?' Scores ranged from 2 to 10 with higher scores indicating greater difficulties with academic functioning. Internal consistency was very good $(\alpha=.83)$.

\section{Coping behaviours.}

Coping behaviours for mental health issues were measured using the Brief Cope Scale (Carver 1997). Participants were asked to consider 'the ways they had been coping with mental health problems in their life'. They rated how often they had been engaging in 21 positive coping behaviours, such as 'I've been getting comfort and understanding from someone', on a 4-point scale ('I haven't been doing this at all' (1) to 'I've been doing this a lot' (4)). Scores ranged between 21 to 84 with higher scores indicating greater use of positive coping behaviours when dealing with mental health issues. Internal consistency was very $\operatorname{good}(\omega=.88)$.

\section{Disclosure.}

Disclosure was measured using the Distress Disclosure Index (Kahn and Hessling 2001). Participants rated agreement with 12 statements such as 'When I feel upset, I usually confide in my friends' on a 5-point scale ('strongly disagree' (1) to 'strongly agree' (5)). Scores were summed to obtain a total ranging from 12 to 60 , with higher scores indicating more disclosure. Internal consistency was excellent $(\omega=.94)$.

Current mental health symptoms. 
Depression, anxiety and stress were measured using the short-form version of the DASS (DASS-21; Henry and Crawford 2005). Participants rated 21 statements on a 4-point scale ('did not apply to me at all' (0) to 'applied to me very much or most of the time' (3)). There were three subscales with seven items each, corresponding to depression, anxiety and stress. Scores were summed for each subscale and multiplied by two to derive three totals ranging from 0 to 42. Higher scores represented higher symptoms of depression, anxiety and stress respectively. Internal consistency was excellent for the depression subscale $(\omega=.92)$, very good for the anxiety subscale $(\omega=.88)$ and stress scale $(\omega=.87)$.

Participants were asked to self-report previously diagnosed mental health conditions. Details were recorded on specific diagnoses and age of diagnosis. Participants were also asked whether they believed that they had an undiagnosed mental health condition, indicated which condition they suspected, and whether they were seeking diagnosis.

\section{Procedure}

The current study used a participatory approach (Cornwall and Jewkes 1995), putting students at the centre of this research. Four students were the experts on student mental health and worked with an academic as researchers to develop the aims of the project. First, the group discussed the problem that needed addressed. Based on lived and peer experience, the group identified that accessing mental health services and the need for support should be the research focus, given the high prevalence of mental health problems for students.

Specifically, the aim was to investigate the barriers that may prevent students from accessing support.

Second, the group investigated the pre-existing literature to establish current knowledge regarding the aim, and to identify how the current study could add to the literature. The group also researched potential barriers to accessing support. Next, the group 
decided how to address the aim. Quantitative questionnaire methods were deemed appropriate and could be used to reach a large sample of students.

In the survey, participants first completed demographic information (including about their studies) and information about their mental health conditions, if applicable. Participants were then asked whether they had received support for their mental health during their time at university. Participants then completed measures on educational impact, self-stigma, perceived stigma, current mental health, coping behaviour, disclosure and help-seeking intentions. The survey took approximately 30 minutes and was part of a larger study with some data not reported here. Upon completion, participants were debriefed, signposted to useful resources and had the option to enter a prize draw. Data was collected between December 2017 and February 2018.

\section{Design}

A cross-sectional survey was used to examine the barriers to students accessing support for mental health. Hierarchical linear regression was used to test whether the proposed variables stigma, self-stigma, educational impact, coping behaviour, disclosure and depressive, anxiety and stress symptoms - could predict help-seeking. Binary logistic regression was used to test whether these variables could predict whether participants had sought help for mental health issues while at university. 


\section{Results}

\section{Mental health conditions.}

In the sample, $40.2 \%(n=151)$ self-reported a diagnosed mental health condition. Specific conditions reported are detailed in Table 2. For undiagnosed conditions, 29 participants (7.7\%) reported that they suspected a mental health condition and were currently seeking diagnosis. Further, 137 participants $(36.4 \%)$ reported that they suspected a mental health condition but were not seeking diagnosis. 55.9\% $(n=210)$ did not suspect an undiagnosed mental health condition. The most commonly suspected conditions were anxiety and mood disorders (Table 2). Overall, 55.9\% $(n=210)$ had accessed support for their mental health since they had been at university.

\section{[Insert Table 2 here]}

\section{Barriers to mental health support.}

Intentions to seek help.

First, three separate hierarchical linear regressions were used, with help-seeking intention scores (formal, informal or no-one) as the outcome variables. In the first step for all regressions, age, gender, previous diagnosis (yes/no) and suspected diagnosis (yes/no) were entered. In the second step, educational impact, perceived stigma, self-stigma, disclosure, coping, depression, anxiety and stress scores were entered.

For help seeking intentions from formal sources, the first step explained $8.3 \%$ of the variance in intentions, and the model was significantly better at predicting the outcome than the mean alone $(\mathrm{F}(4,341)=7.65, p<.001)$. The final model explained $16.0 \%$ of the variance (a significant increase, $p<.001)$ and the model was significant $(\mathrm{F}(12,341)=5.24, p<.001)$. 
In the final model (Table 3), gender was a significant predictor of intentions, with male participants $(\mathrm{M}=34.03, S D=6.73)$ more likely to intend to seek help than female participants $(\mathrm{M}=31.26, S D=6.45)$. Those with a diagnosed mental health condition $(\mathrm{M}=$ $10.38, S D=4.05)$ were more likely to intend to formally seek help than those who did not (M $=8.55, S D=4.15)$. Self-stigma significantly predicted help-seeking intentions, such that with increasing self-stigma, help-seeking intentions decreased. With increasing educational impact and perceived public stigma, help-seeking intentions from formal sources significantly increased.

[Insert Table 3 here]

For help seeking intentions from informal sources, the first step explained $14.4 \%$ of the variance in help-seeking intentions, with the model significantly better at predicting the outcome than the mean alone $(\mathrm{F}(4,337)=14.00, p<.001)$. The final model explained $41.2 \%$ of the variance (significant increase, $p<.001)$ and was significant $(\mathrm{F}(12,337)=19.00$, $p<.001)$

In the final model (Table 3), age was a significant predictor of intentions to seek help from informal sources, such that with age participants were less likely to seek help from informal sources. Those who suspected an undiagnosed mental health condition $(M=15.75$, $S D=4.87)$ were less likely to intend to seek help from informal sources than those who did not $(\mathrm{M}=18.82, S D=4.85)$. Disclosure significantly predicted help-seeking intentions, such that with increasing disclosure, help-seeking intentions increased. With increasing stress, help-seeking intentions from informal sources increased, but with increasing depression symptoms, intentions significantly decreased.

For help seeking intentions from no-one, the first step explained $4.3 \%$ of the variance in non-help-seeking intentions, and the model was significantly better at predicting the 
outcome than the mean alone $(\mathrm{F}(4,338)=3.79, p=.005)$. The final model explained $45.4 \%$ of the variance (significant increase, $p<.001)$ and was significant $(\mathrm{F}(12,338)=22.57$, $p<.001)$.

Self-stigma was a significant predictor of intentions to not seek help in the final model (Table 3): with increasing self-stigma, the likelihood of not seeking help increased. With increasing depression symptoms, intentions to not seek help significantly increased. With increasing disclosure, intentions to not seek help decreased.

Actual help-seeking behaviour. The variables which could predict actual help-seeking behaviour were examined. Descriptive statistics for each variable according to whether the participants had accessed support, are shown in Table 4.

\section{[Insert Table 4 here]}

Binary logistic regression was used to test whether the variables could predict whether or not participants had accessed support for their mental health while at university. The predictors entered were age, gender, previous diagnosis, suspected undiagnosed condition, educational impact, perceived public stigma, self-stigma, help-seeking intentions (formal, informal and no-one), disclosure, coping, depression, anxiety and stress. Results are shown in Table 5.

\section{[Insert Table 5 here]}

Those with a previous diagnosis were 4.24 times more likely to access support since they had been at university, and those who suspected an undiagnosed mental health condition were 2.41 times more likely than those who did not. With increasing educational impact, help-seeking intentions from formal sources and stress symptoms, the odds of accessing support increased. With increasing self-stigma, the odds of accessing support decreased. 


\section{Discussion}

This study examined potential barriers preventing students from accessing mental health support. The examined barriers included perceived public stigma, self-stigma, educational impact, disclosure, coping and current mental health symptoms. In the study, four in ten participants reported a diagnosed mental health condition, with anxiety and mood disorders commonly reported. Further, a third of participants suspected a mental health condition, but were not seeking a diagnosis, and only $8 \%$ were seeking a diagnosis. Over half of the sample $(55 \%)$ had accessed support for their mental health since being at university. In analyses examining the barriers to accessing support, both in terms of intentions to seek help and actual help-seeking behaviour, self-stigma associated with seeking help was a significant barrier.

Self-stigma was a significant predictor of a lack of help-seeking intentions and actual help-seeking behaviour, suggesting that self-stigma attached to help-seeking affects both intentions and behaviour. This finding supports previous qualitative research (Quinn et al. 2009) and research with non-student populations (Bathje and Pryor 2011; Gulliver et al. 2010). Corrigan (2004) suggests that self-stigmatising mental health issues affects selfesteem, linking to feeling ashamed and demoralised. Tucker et al. (2013) noted that selfstigma around seeking help (rather than self-stigma of having a mental illness) relates to selfblame and explains more variance in help-seeking intentions - such that the act of helpseeking is the barrier, rather than being labelled 'mentally ill'. The current study measured only self-stigma of seeking help, therefore future studies would benefit from also measuring the self-stigma of mental illness. Nonetheless, the current findings indicate that the selfstigma of seeking help acts as a barrier to accessing support. 
Notably, self-stigma did not predict help seeking intentions from informal sources. This finding may relate to informal sources offering help only in the form of social support. Indeed, with greater disclosure, participants were more likely to seek help from informal sources, but disclosure did not predict help-seeking from formal sources. This supports prior research that family and friends are more often recipients of disclosure than professionals for those with suicidal ideation (Husky et al. 2016) and severe mental illnesses, with higher levels of disclosure associated with higher perceived social support (Pahwa et al. 2017). Disclosure to family and friends is thought to be beneficial due to the empathy received upon disclosure (Bril-Barniv et al. 2017).

Notably, only intentions to seek help from formal sources predicted actual helpseeking behaviour. Together, these findings suggest that disclosing mental health issues to informal sources does not necessarily relate to actual help-seeking. Nonetheless, social support is still important in mental health recovery (Hendryx, Green and Perrin 2009). For young people, Gulliver et al. (2010) found a preference to seek help from family and friends rather than professionals. Gulliver et al. (2012) also found that people are more likely to seek help from informal sources who provide social support rather than professionals.

Nevertheless, help-seeking from professional services is a fundamental pathway towards support for mental health issues.

While self-stigma and public stigma are separate but interrelated concepts (Corrigan 2004), perceived public stigma only positively predicted help-seeking intentions from formal sources. Perceived public stigma did not predict intentions in other analyses, nor did it predict actual help-seeking behaviour. Previous studies have found the perceived public stigma does not predict help-seeking in students (Eisenberg et al. 2009). Further, Vogel et al. (2006) found that self-stigma fully mediates the relationship between public stigma and help-seeking intentions for students. Together, these findings suggest that self-stigma - although 
influenced by perceived public stigma - is a significant barrier to support for students, and more research is needed to understand the relationship between stigma and mental health in students.

Educational impact was also a significant predictor of actual help-seeking behaviour and help-seeking intentions from formal sources. As mental health issues begin to affect academic performance, it makes sense that students would be more inclined to seek help. This finding also demonstrates the impact mental health conditions could have on academic functioning - such as reducing concentration and motivation and increasing fatigue and social withdrawal (Kitzrow 2003). Positively, with increasing educational impact participants were more likely to seek help - suggesting that they feel able to seek help when their studies are affected. However, this finding may also indicate that more needs to be done to prevent mental health problems affecting academic studies in the first place. Interventions focusing on improving students' resilience to academic-related stress may be beneficial (Hartley 2011).

In terms of mental health symptoms, increasing depressive symptoms predicted decreased help-seeking from informal sources and increased likelihood of seeking help from no-one. With depression, symptoms such as feeling guilty may relate to decreased motivation to seek help (D’Avanzo et al., 2012). Barney et al. (2009) found that participants were reluctant to talk to informal sources about depression due to concerns over appearing 'weak' or being 'viewed less' as a person. For actual help-seeking, increasing stress symptoms predicted greater likelihood of accessing support. As stress levels rise, seeking support to manage stress may be less stigmatised than depression, however greater understanding of stress at university is needed (Robotham and Julian 2006). 
In this study, regardless of whether they were accessing support or not, participants reported high rates of depression, anxiety and stress in comparison to general population means (Henry and Crawford 2005). Many were therefore experiencing elevated levels of mental health symptoms, yet may not perceive that they need help or believe that their experience is "normal" (Brown 2018). These findings may reflect normalisation of the narrative around elevated mental health issues in students. In general, mental health conditions are more prevalent and have their onset in adolescence or young adulthood (Patel et al. 2007). However, circumstances at universities in the UK, such as academic pressures and financial issues, may exacerbate mental health issues (Brown 2016). An Australian study comparing students to age-matched non-students, found that mental health conditions were more prevalent in students (Stallman 2011). In UK universities, $21 \%$ of students rated themselves as having low anxiety, compared to $43 \%$ of age-matched non-students (Brown 2016). These findings suggest there are specific stressors within universities that aggravate mental health issues.

Finally, previous diagnosis predicted help-seeking intentions from formal sources and actual help-seeking behaviour. In Hartrey, Denieffe and Wells' (2017) systematic review, students with good previous experience of mental health services were more likely to seek help than those who were not familiar with these services. In the current study those who suspected a mental health condition were less likely to intend to seek help from informal sources, but they were more likely to have sought actual help. One explanation is that these individuals felt that formal support would be more beneficial to them than informal support.

\section{Limitations and future research}

One significant limitation of the current study is its generalisability. Most participants attended universities in South East England, reflecting the location of the study authors. Most 
were also White British. Mental health statistics in England vary by ethnicity: Black, Asian and mixed-race individuals report more mental health concerns than White people (Baker 2018). Another limitation is that most participants were female. Women are more likely to take part in survey research (Sax, Gilmartin and Bryant 2003) and the topic may have been of greater interest to females, who are more likely to experience internalising problems (Kuehner 2003). Despite the limited generalisability, the current study still has value in understanding the barriers some students face.

The study also assumes no change in mental health issues or help-seeking behaviours during the academic year. Knoesen and Naude (2012) found that first-year students initially 'languished' and struggled academically, however over the academic year developed skills that allowed them to 'flourish'. Brown (2018) suggests that longitudinal research would indicate such fluctuations and provide better understanding of mental health problems at university. Thus, future longitudinal research would be highly beneficial.

Future research should also examine ways of reducing the self-stigma. Those with mental health conditions who self-stigmatise commonly state that treatment provides little personal empowerment, linking to reduced motivation to seek treatment (Corrigan 2004). Therefore, interventions that target self-stigma and increase personal empowerment may increase help-seeking behaviour. Lucksted et al. (2011) piloted an intervention to reduce selfstigma in those with mental illnesses and found a significant decrease in self-stigma and increase in personal empowerment after the intervention. Future research should endeavour to test further interventions in this area.

\section{Conclusion}

Overall, the current study identified possible barriers preventing students from accessing support, both in terms of help-seeking intentions and actual help-seeking behaviour. Self- 
stigma was a significant barrier of help-seeking behaviour, and disclosure, educational impact, previous diagnosis, suspected diagnosis and current mental health symptomology also interacted with help-seeking. This study makes an important contribution in deepening our understanding of the barriers faced by UK students in relation to mental health. More work needs to be done, however, on taking down these barriers, and promoting better student wellbeing.

\section{Acknowledgements}

Thank you to all of the participants in this study and peers and colleagues for their support in recruitment.

\section{Declaration of interest}

This work received no grant funding support. The authors have no conflicts of interest to declare. 


\section{References}

Abraham, Charles, Paschal Sheeran, and Marion Henderson. 2011. 'Extending Social Cognition Models of Health Behaviour'. Health Education Research 26 (4): 624-637. https://doi.org/10.1093/her/cyr018.

Baker, Carl. 2018. Mental Health Statistics For England: Prevalence, Services And Funding. House of Commons Library. Accessed 8 August 2018. http://researchbriefings.files.parliament.uk/documents/SN06988/SN06988.pdf

Barney, L.J., Griffiths, K.M., Christensen, H., and Jorm, A.F. 2009. 'Exploring the nature of stigmatising beliefs about depression and help-seeking: Implications for reducing stigma’. BMC Public Health 9: 61 https://doi.org.10.1186/1471-2458-9-61.

Bathje, Geoff, and John Pryor. 2011. 'The Relationships Of Public And Self-Stigma To Seeking Mental Health Services'. Journal Of Mental Health Counselling 33 (2): 161176. https://doi:10.17744/mehc.33.2.g632039274160411.

Bril-Barniv, Shani, Galia S. Moran, Adi Naaman, David Roe, and Orit Karnieli-Miller. 2017. 'A Qualitative Study Examining Experiences and Dilemmas in Concealment and Disclosure of People Living With Serious Mental Illness'. Qualitative Health Research 27 (4): 573-83. https://doi.org/10.1177/1049732316673581.

Brown, P. 2016. The invisible problem? Improving students' mental health. Higher Education Policy Institute. Accessed 31 July 2018. https://www.hepi.ac.uk/wpcontent/uploads/2016/09/STRICTLY-EMBARGOED-UNTIL-22-SEPT-Hepi-Report88-FINAL.pdf 
Brown, June S. L. 2018. 'Student Mental Health: Some Answers and More Questions'. Journal of Mental Health 27 (3): 193-96. https://doi.org/10.1080/09638237.2018.1470319.

Carver, Charles S. 1997. 'You Want to Measure Coping but Your Protocol' Too Long: Consider the Brief Cope'. International Journal of Behavioural Medicine 4 (1): 92. https://doi.org/10.1207/s15327558ijbm0401_6.

Carver, Charles S., and Jennifer Connor-Smith. 2010. 'Personality and Coping'. Annual Review of Psychology 61 (1): 679-704. https://doi.org/10.1146/annurev.psych.093008.100352.

Clement, S., O. Schauman, T. Graham, F. Maggioni, S. Evans-Lacko, N. Bezborodovs, C. Morgan, N. Rüsch, J. S. L. Brown, and G. Thornicroft. 2015. 'What Is the Impact of Mental Health-Related Stigma on Help-Seeking? A Systematic Review of Quantitative and Qualitative Studies'. Psychological Medicine 45 (1): 11-27. https://doi.org/10.1017/S0033291714000129.

Cornwall, Andrea, and Rachel Jewkes. 1995. 'What is Participatory Research?' Social Science \& Medicine 41 (12): 1667-1676. https://doi.org/10.1016/02779536(95)00127-S.

Corrigan, Patrick. 2004. 'How Stigma Interferes with Mental Health Care'. The American Psychologist 59 (7): 614-25. https://doi.org/10.1037/0003-066X.59.7.614.

Corrigan, Patrick, Amy C. Watson, and Leah Barr. 2006. 'The Self-Stigma of Mental Illness: Implications for Self-Esteem and Self-Efficacy’. Journal of Social and Clinical Psychology 25 (8): 875-84. https://doi.org/10.1521/jscp.2006.25.8.875. 
Czyz, Ewa K., Adam G. Horwitz, Daniel Eisenberg, Anne Kramer, and Cheryl A. King. 2013. 'Self-Reported Barriers to Professional Help Seeking Among College Students at Elevated Risk for Suicide'. Journal of American College Health 61 (7): 398-406. https://doi.org/10.1080/07448481.2013.820731.

D'Avanzo, B., Barbato, A., Erzegovesi, S., Lampertico, L., Rapisarda, F., and Valsecchi, L. 2012. 'Formal and Informal Help-Seeking for Mental Health Problems. A survey of preferences of Italian Students'. Clinical Practice \& Epidemiology in Mental Health 8: 47-51. https://doi: 10.2174/1745017901208010047.

de Bruijn, Gert-Jan, Kim Out, and Ryan E. Rhodes. 2014. 'Testing The Effects Of Message Framing, Kernel State, And Exercise Guideline Adherence On Exercise Intentions And Resolve'. British Journal Of Health Psychology 19 (4): 871-885. https://doi:10.1111/bjhp.12086.

Eisenberg, Daniel, and Henry Chung. 2012. 'Adequacy of Depression Treatment among College Students in the United States'. General Hospital Psychiatry 34 (3): 213-20. https://doi.org/10.1016/j.genhosppsych.2012.01.002.

Eisenberg, Daniel, Marilyn F. Downs, Ezra Golberstein, and Kara Zivin. 2009. 'Stigma and Help Seeking for Mental Health Among College Students, Stigma and Help Seeking for Mental Health Among College Students'. Medical Care Research and Review 66 (5): 522-541. https://doi.org/10.1177/1077558709335173.

Eisenberg, Daniel, Ezra Golberstein, and Sarah E. Gollust. 2007. 'Help-Seeking and Access to Mental Health Care in a University Student Population'. Medical Care 45 (7): 594 601. https://doi.org/10.1097/MLR.0b013e31803bb4c1.

Eskin, Mehmet, Jian-Min Sun, Jamila Abuidhail, Kouichi Yoshimasu, Omar Kujan, Mohsen Janghorbani, Chris Flood, et al. 2016. 'Suicidal Behavior and Psychological Distress 
in University Students: A 12-Nation Study'. Archives of Suicide Research 20 (3): 369-388. https://doi.org/10.1080/13811118.2015.1054055.

Golberstein, Ezra, Daniel Eisenberg, and Sarah E. Gollust. 2008. 'Perceived Stigma and Mental Health Care Seeking'. Psychiatric Services 59 (4): 392-399. https://doi.org/10.1176/ps.2008.59.4.392.

Gulliver, Amelia, Kathleen M. Griffiths, and Helen Christensen. 2010. 'Perceived Barriers and Facilitators to Mental Health Help-Seeking in Young People: A Systematic Review'. BMC Psychiatry 10 (1): 113. https://doi.org/10.1186/1471-244X-10-113.

Gulliver, Amelia, Kathleen M. Griffiths, Helen Christensen, and Jacqueline L. Brewer. 2012. 'A Systematic Review of Help-Seeking Interventions for Depression, Anxiety and General Psychological Distress’. BMC Psychiatry 12 (1): 81. https://doi.org/10.1186/1471-244X-12-81.

Hartley, Michael T. 2011. 'Examining the relationships between resilience, mental health, and academic persistence in undergraduate college students.' Journal of American College Health 59, (7): 596-604. https://doi: 10.1080/07448481.2010.515632.

Hartrey, Laura, Suzanne Denieffe, and John S. G. Wells. 2017. 'A Systematic Review of Barriers and Supports to the Participation of Students with Mental Health Difficulties in Higher Education'. Mental Health \& Prevention 6: 26-43. https://doi.org/10.1016/j.mhp.2017.03.002.

Hendryx, Michael, Carla A. Green, and Nancy A. Perrin. 2009. "Social Support, Activities, And Recovery From Serious Mental Illness: STARS Study Findings". The Journal Of Behavioral Health Services \& Research 36 (3): 320-329. https://doi:10.1007/s11414008-9151-1. 
Henry, Julie D., and John R. Crawford. 2005. 'The Short-Form Version of the Depression Anxiety Stress Scales (DASS-21): Construct Validity and Normative Data in a Large Non-Clinical Sample’. British Journal of Clinical Psychology 44 (2): 227-239. https://doi.org/10.1348/014466505X29657.

Higher Education Statistics Authority. 2018. Higher Education Student Statistics: UK, 201617 - student numbers and characteristics. HESA. Accessed 31 July 2018. https://www.hesa.ac.uk/news/11-01-2018/sfr247-highereducation-studentstatistics/numbers

Husky, Mathilde M., Ingrid Zablith, Victor Alvarez Fernandez, and Viviane Kovess-Masfety. 2016. 'Factors Associated with Suicidal Ideation Disclosure: Results from a Large Population-Based Study'. Journal of Affective Disorders 205: 36-43. https://doi.org/10.1016/j.jad.2016.06.054.

Kahn, Jeffrey H., and Robert M. Hessling. 2001. 'Measuring the Tendency to Conceal Versus Disclose Psychological Distress'. Journal of Social and Clinical Psychology 20 (1): 41-65. https://doi.org/10.1521/jscp.20.1.41.22254.

Kitzrow, Martha Anne. 2003 'The mental health needs of today's college students: Challenges and recommendations'. NASPA Journal, 41 (1): 167-181. https://doi: $10.2202 / 1949-6605.5037$.

Knoesen, R., and Naude, L. 2017. 'Experiences of flourishing and languishing during the first year at university'. Journal of Mental Health 27 (3): 269-278. https://doi.org/10.1080/09638237.2017.1370635.

Kuehner, Christine. 2003. 'Gender differences in unipolar depression: an update of epidemiological findings and possible explanations.' Acta Psychiatrica Scandinavica 108 (3): 163-174. https://doi.org/10.1034/j.1600-0447.2003.00204.x. 
Lucksted, Alicia, Amy Drapalski, Christine Calmes, Courtney Forbes, Bruce DeForge, and Jennifer Boyd. 2011. 'Ending self-stigma: Pilot evaluation of a new intervention to reduce internalized stigma among people with mental illnesses.' Psychiatric Rehabilitation Journal 35 (1): 51. https://doi: 10.2975/35.1.2011.51.54.

Mackay, James, Susan T. Charles, Bryan Kemp, and Jutta Heckhausen. 2011. 'Goal Striving and Maladaptive Coping in Adults Living With Spinal Cord Injury: Associations With Affective Well-Being, Goal Striving and Maladaptive Coping in Adults Living With Spinal Cord Injury: Associations With Affective Well-Being'. Journal of Aging and Health 23 (1): 158-176. https://doi.org/10.1177/0898264310382039.

Montano, D.E., and Kasprzyk, D. 2015. Theory of Reasoned Action, Theory of Planned Behaviour, and the Integrated Behavioural Model. In K. Glanz, B.K. Rimer, and K. "V". Viswanath (Eds.), Health behavior: Theory, research, and practice (pp. 95-124). San Francisco, CA, US: Jossey-Bass.

Monzani, Dario, Patrizia Steca, Andrea Greco, Marco D’Addario, Erika Cappelletti, and Luca Pancani. 2015. 'The Situational Version of the Brief COPE: Dimensionality and Relationships with Goal-Related Variables'. Europe's Journal of Psychology 11 (2): 295-310. https://doi.org/10.5964/ejop.v11i2.935.

Mowbray, Carol T., Deborah Megivern, James M. Mandiberg, Shari Strauss, Catherine H. Stein, Kim Collins, Sandra Kopels, Caroline Curlin, and Robin Lett. 2006. 'Campus Mental Health Services: Recommendations for Change'. American Journal of Orthopsychiatry 76 (2): 226-237. https://doi.org/10.1037/0002-9432.76.2.226.

NUS-USI. 2017. Student Wellbeing Research Report. National Union of Students. Accessed 31 July 2018. https://nusdigital.s3-eu-west- 
1.amazonaws.com/document/documents/33436/59301ace47d6320274509b83e1bea53 e/NUSUSI_Student_Wellbeing_Research_Report.pdf

Pahwa, Rohini, Anthony Fulginiti, John S. Brekke, and Eric Rice. 2017. 'Mental Illness Disclosure Decision Making'. The American Journal of Orthopsychiatry 87 (5): 575584. https://doi.org/10.1037/ort0000250.

Patel, Vikram, Alan J Flisher, Sarah Hetrick, and Patrick McGorry. 2007. 'Mental Health of Young People: A Global Public-Health Challenge'. The Lancet 369 (9569): 13021313. https://doi.org/10.1016/S0140-6736(07)60368-7.

Quinn, Neil, Alistair Wilson, Gillian MacIntyre, and Teresa Tinklin. 2009. "“People Look at You Differently": Students’ Experience of Mental Health Support within Higher Education'. British Journal of Guidance \& Counselling 37 (4): 405-418. https://doi.org/10.1080/03069880903161385.

Rickwood, Debra, Frank P. Deane, Coralie J. Wilson, and Joseph Ciarrochi. 2005. 'Young people's help-seeking for mental health problems.' Australian e-journal for the Advancement of Mental health 4 (3): 218-251. https://doi.org/10.5172/jamh.4.3.218.

Robotham, David, and Claire Julian. 2006. 'Stress and the higher education student: a critical review of the literature.' Journal of further and higher education, 30 (2): 107-117. https://doi.org/10.1080/03098770600617513.

Rosenthal, Beth, and Cody Wilson. 2008. 'Mental Health Services: Use and Disparity Among Diverse College Students'. Journal of American College Health 57 (1): 61-68. https://doi.org/10.3200/JACH.57.1.61-68. 
Sax, Linda J., Shannon K. Gilmartin, and Alyssa N. Bryant. 2003. 'Assessing response rates and nonresponse bias in web and paper surveys.' Research in higher education, 44 (4): 409-432. https://doi.org/10.1023/A:1024232915870

Stallman, Helen M. 2010. 'Psychological Distress in University Students: A Comparison with General Population Data'. Australian Psychologist 45 (4): 249-257. https://doi.org/10.1080/00050067.2010.482109.

Struthers, C. Ward, Raymond P. Perry, and Verena H. Menec. 2000. 'An Examination of the Relationship Among Academic Stress, Coping, Motivation, and Performance in College'. Research in Higher Education 41 (5): 581-592. https://doi.org/10.1023/A:1007094931292.

Thorley, Craig. 2017. Not by degrees: Improving student mental health in the UK's universities. Institute for Public Policy Research. Accessed 31 July 2018. https://www.ippr.org/files/2017-09/1504645674_not-by-degrees-170905.pdf

Tucker, Jeritt R., Joseph H. Hammer, David L. Vogel, Rachel L. Bitman, Nathaniel G. Wade, and Emily J. Maier. 2013. ‘Disentangling Self-Stigma: Are Mental Illness and HelpSeeking Self-Stigmas Different?’ Journal of Counselling Psychology 60 (4): 520-531. https://doi.org/10.1037/a0033555.

Vidourek, Rebecca A., Keith A. King, Laura A. Nabors, and Ashley L. Merianos. 2014. 'Students’ Benefits and Barriers to Mental Health Help-Seeking’. Health Psychology and Behavioural Medicine 2 (1): 1009-1022. https://doi.org/10.1080/21642850.2014.963586.

Vogel, David L., Nathaniel G. Wade, and Shawn Haake. 2006. 'Measuring the Self-Stigma Associated with Seeking Psychological Help'. Journal of Counselling Psychology 53 (3): 325-337. https://doi.org/10.1037/0022-0167.53.3.325. 
Wilson, Coralie J., Frank P. Deane, Joseph Ciarrochi, and Debra Rickwood. 2005.

'Measuring Help-Seeking Intentions: Properties of the General Help Seeking

Questionnaire'. Canadian Journal of Counselling and Psychotherapy 39 (1): 15.

https://cjc-rcc.ucalgary.ca/cjc/index.php/rcc/article/view/265. 
Table 1. Demographic information on university and student status variables.

\begin{tabular}{ll}
\hline & Percentage \\
\hline Region of university & \\
South East England & 65.3 \\
East and West Midlands & 7.2 \\
Wales & 6.8 \\
South West England & 6.1 \\
London & 5.1 \\
Yorkshire and the Humber & 3.2 \\
North West and North East England & 4.3 \\
Scotland & 1.2 \\
East of England & 0.8 \\
Student status & \\
Home & 86.2 \\
EU & 9 \\
International & 4.8 \\
Study status & \\
Full-time & 97.9 \\
Part-time & 1.9 \\
Other & .3 \\
Level of study & 89.1 \\
Undergraduate & 6.6 \\
Postgraduate taught (e.g. Masters) & 3.7 \\
Postgraduate research (e.g. PhD) & .5 \\
Other & \\
Current year of study & 26.6 \\
Year one & 39.6 \\
Year two & 5.1 \\
Year three & .3 \\
Year four & \\
Other & \\
\hline & \\
\hline
\end{tabular}


Table 2. Diagnosis details, including mean age of diagnosis, and suspected diagnoses. Note: participants could report more than one condition.

\begin{tabular}{llll}
\hline Condition & $\begin{array}{l}N \text { diagnosed } \\
(\%)\end{array}$ & $\begin{array}{l}\text { Mean }(S D) \text { age of } \\
\text { diagnosis }\end{array}$ & $\begin{array}{l}N \text { suspected } \\
\text { diagnosis }(\%)\end{array}$ \\
\hline Anxiety disorder & $114(30.3 \%)$ & $17.19(4.65)$ & $96(25.5 \%)$ \\
Mood disorder & $84(22.3 \%)$ & $16.96(4.26)$ & $64(17 \%)$ \\
Eating disorder & $30(8 \%)$ & $16.20(3.01)$ & $18(4.8 \%)$ \\
Obsessive Compulsive Disorder & $22(5.9 \%)$ & $17.77(8.94)$ & $16(4.3 \%)$ \\
Personality disorder & $14(3.7 \%)$ & $20.58(7.83)$ & $14(3.7 \%)$ \\
Post-Traumatic Stress Disorder & $14(3.7 \%)$ & $18.38(3.15)$ & $12(3.2 \%)$ \\
Autism Spectrum Condition & $8(2.1 \%)$ & $22.50(13.43)$ & $7(1.9 \%)$ \\
Psychotic Disorder & $6(1.6 \%)$ & $22.17(11.44)$ & $1(.3 \%)$ \\
Other & $4(1.6 \%)$ & $17.75(9.03)$ & $7(1.9 \%)$ \\
Addiction disorder & $3(.8 \%)$ & $17.00(1.00)$ & $7(1.9 \%)$ \\
Tourette's Syndrome & $2(.5 \%)$ & $15.50(3.54)$ & $1(.3 \%)$ \\
\hline
\end{tabular}


Table 3. Hierarchical linear regression predicting help-seeking intentions from formal sources, informal sources and 'no-one'.

\begin{tabular}{|c|c|c|c|c|c|c|c|c|c|}
\hline & \multicolumn{3}{|c|}{$\begin{array}{l}\text { Help-seeking intentions: } \\
\text { Formal sources }\end{array}$} & \multicolumn{3}{|c|}{$\begin{array}{l}\text { Help-seeking intentions: } \\
\text { Informal sources }\end{array}$} & \multicolumn{3}{|c|}{$\begin{array}{l}\text { Help-seeking intentions } \\
\text { No-one }\end{array}$} \\
\hline & $\mathrm{B}$ & $S E \mathrm{~B}$ & $\beta$ & $\mathrm{B}$ & $S E \mathrm{~B}$ & $\beta$ & B & $S E \mathrm{~B}$ & $\beta$ \\
\hline \multicolumn{10}{|l|}{ Step One } \\
\hline Age & -.002 & .065 & -.002 & -.17 & .076 & $-.12 *$ & .009 & .031 & .017 \\
\hline Gender & 2.18 & .60 & $.19 * * *$ & -.21 & .70 & -.016 & .42 & .29 & .081 \\
\hline Previous diagnosis & -2.17 & .47 & $-.25^{* * *}$ & 2.12 & .55 & $.21 * * *$ & -.29 & .22 & -.072 \\
\hline Undiagnosed condition & -.12 & .45 & -.015 & -3.33 & .52 & $-.33 * * *$ & .77 & .21 & $.19 * * *$ \\
\hline \multicolumn{10}{|l|}{ Step Two } \\
\hline Age & -.026 & .064 & -.021 & -.16 & .065 & $-.11 *$ & .006 & .024 & .010 \\
\hline Gender & 2.25 & .61 & $.20 * * *$ & .31 & .62 & .023 & .20 & .23 & .038 \\
\hline Previous diagnosis & -1.34 & .54 & $-.16^{*}$ & .76 & .54 & .074 & .042 & .20 & .011 \\
\hline Undiagnosed condition & -.21 & .48 & -.025 & -1.85 & .49 & $-.18^{* * *}$ & .16 & .18 & .040 \\
\hline Educational impact & .30 & .12 & $.18^{*}$ & -.19 & .12 & -.091 & -.028 & .045 & -.036 \\
\hline Perceived public stigma & .13 & .062 & $.12 *$ & -.026 & .062 & -.020 & -.006 & .023 & -.011 \\
\hline Self-stigma & -.13 & .035 & $-.22 * * *$ & -.027 & .035 & -.039 & .040 & .013 & $.15^{* *}$ \\
\hline Disclosure & .041 & .023 & .11 & .17 & .023 & $.37 * * *$ & -.097 & .008 & $-.54 * * *$ \\
\hline Coping & -.026 & .023 & -.067 & .036 & .023 & .076 & -.001 & .009 & -.006 \\
\hline Depression & -.031 & .031 & -.083 & -.11 & .031 & $-.25^{* * *}$ & .039 & .012 & $.23 * * *$ \\
\hline Anxiety & .035 & .032 & .087 & -.038 & .032 & -.079 & -.005 & .012 & -.025 \\
\hline Stress & .003 & .040 & .008 & .089 & .040 & $.17 *$ & -.017 & .015 & -.086 \\
\hline
\end{tabular}

Note: $* * * p<.001 * * p=.002 * p<.05$ 
Table 4. Descriptive statistics for the barriers for individuals who had or had not accessed support for their mental health since being at university.

\begin{tabular}{|c|c|c|c|}
\hline & \multirow{3}{*}{$\begin{array}{l}\text { Total Mean } \\
(S D)\end{array}$} & \multicolumn{2}{|c|}{$\begin{array}{l}\text { Have you accessed support for your } \\
\text { mental health since you have been at } \\
\text { university? }\end{array}$} \\
\hline & & Yes $(n=210)$ & No $(n=163)$ \\
\hline & & Mean $(S D)$ & Mean $(S D)$ \\
\hline Help-seeking intentions: Formal & $9.29(4.21)$ & $10.30(4.14)$ & $7.89(3.86)$ \\
\hline Help-seeking intentions: Informal & $17.45(5.09)$ & $16.91(5.00)$ & $18.10(5.14)$ \\
\hline Help seeking intentions: No-one & $3.64(1.97)$ & $3.47(1.89)$ & $3.88(2.06)$ \\
\hline Disclosure & $34.23(10.86)$ & $34.07(10.85)$ & $34.18(10.73)$ \\
\hline Self-stigma & $27.07(7.15)$ & $26.30(6.80)$ & $28.15(7.47)$ \\
\hline Perceived public stigma & $14.64(3.97)$ & $15.09(3.71)$ & $14.09(4.24)$ \\
\hline Coping & $45.51(10.68)$ & $47.33(9.36)$ & $43.30(11.81)$ \\
\hline Educational impact & $5.24(2.48)$ & $6.13(2.42)$ & $4.12(2.07)$ \\
\hline Depression & $17.59(11.51)$ & $20.32(11.46)$ & $14.33(10.67)$ \\
\hline Anxiety & $15.04(10.50)$ & $18.15(10.40)$ & $11.14(9.25)$ \\
\hline Stress & $20.49(10.04)$ & $23.54(9.32)$ & $16.80(9.59)$ \\
\hline
\end{tabular}

Note. Non-clinical population means (SD) for DASS-21 from Henry and Crawford (2005): depression 5.66 (7.74), anxiety $3.76(5.90)$ and stress 9.46 (8.40) 
Table 5. Binary logistic regression examining predictors of accessing support while at university.

\begin{tabular}{lllll}
\hline & & \multicolumn{3}{c}{$95 \%$ CI for Odds Ratio } \\
& $\mathrm{B}(S E)$ & Lower & Odds & Upper \\
& & \multicolumn{3}{c}{ Ratio } \\
\hline Age & $.025(.058)$ & .92 & 1.03 & 1.15 \\
Gender & $.42(.41)$ & .68 & 1.52 & 3.36 \\
Previous diagnosis & $1.49(.35)^{* * *}$ & 2.23 & 4.21 & 8.75 \\
Undiagnosed condition suspected & $.90(.36)^{*}$ & 1.21 & 2.45 & 4.95 \\
Educational impact & $.28(.085)^{* * *}$ & 1.12 & 1.32 & 1.56 \\
Perceived public stigma & $-.008(.043)$ & .93 & 1.01 & 1.10 \\
Self-stigma & $-.054(.025)^{*}$ & .90 & .95 & .99 \\
Help-seeking intentions: Formal & $.12(.039)^{* *}$ & 1.04 & 1.13 & 1.21 \\
Help-seeking intentions: Informal & $-.047(.039)$ & .88 & .95 & 1.03 \\
Help-seeking intentions: No-one & $-.18(.10)$ & .68 & .84 & 1.03 \\
Disclosure & $-.006(.019)$ & .96 & .99 & 1.03 \\
Coping & $.009(.015)$ & .98 & 1.01 & 1.04 \\
Depression & $-.023(.022)$ & .94 & .98 & 1.02 \\
Anxiety & $.023(.022)$ & .98 & 1.02 & 1.07 \\
Stress & $.065(.028)^{*}$ & 1.01 & 1.07 & 1.13 \\
\hline
\end{tabular}

Note $\mathrm{R}^{2}=.38\left(\right.$ Cox and Snell), .51 (Nagelkerke). Model $\chi^{2}(15)=158.97, p<.001 . * * * p<.001$ $* * p=.002 * p<.05$. 